\title{
Research on Training System for Professional Development of Foreign Teachers in Universities
}

\author{
Jinghua Ma \\ School of Humanities and Law \\ Northeastern University \\ Shenyang, China
}

\begin{abstract}
Scientific training system for foreign teachers in universities is important guarantee to promote development of foreign teachers in universities and improve the quality of higher education. Use documentary method and investigation method to reveal problems existing in training for foreign teachers in universities at present such as unclear training objectives, single training contents, formalized training course and backward training assessment methods. In order to make up for defects of training for foreign teachers in universities and solve problems existing in their development, start with training concept, prejob training and on-the-job training and discuss measures that promote training system for development of foreign teachers in universities.
\end{abstract}

Keywords-universities; development of foreign teachers; problems; training system

\section{INTRODUCTION}

Economic globalization promotes internationalization development of higher education and exchanges of different countries on educational resources increasingly strengthen, so internationalization of higher education has become an irresistible trend. [1] Universities are the main base for our country to cultivate talents. The quality of teachers determines the quality of talent cultivation. Internationalization of teaching body in universities is the most basic condition to ensure internationalization of higher education. In internationalized teaching body in universities of China, foreign teachers have become important part of education and economic development service of our country. However, because of differences in language and culture, it is difficult for foreign teachers employed by universities to rapidly adapt to teaching and life in universities of our country, which hinder professional development of foreign teachers in universities. In view of this, it has important value on effectively governing foreign teachers and promoting their development by exploring on scientific and reasonable management mechanism for foreign teachers in universities that can help the development of foreign teachers.

Fund program: Research result of humanistic and social science research plan of Ministry of Education on "Research on Theory and Method to Improve Performance of Teachers in Universities" (13YJA880064); research result of culture and education subject of State Bureau of Foreign Experts Affairs "Investigation on Teaching Situation of Foreign Teachers in China in Higher Education - Research by Taking Foreigners in Liaoning Province of China as Individual Case" (Culture and Education Subject of Bureau of Foreign Experts Affairs [2011] No. 102).

\section{DEFINITION OF CORE CONCEPT}

\section{A. Foreign Teachers in Universities}

Foreign teachers in universities refer to professionals who are employed by universities of our country and work on language teaching or professional teaching in universities of our country. At present, our country should base on practical situation of national conditions, renovate previous training ideas and ways, continuously improve enthusiasm of foreign teachers for autonomous development and then improve the quality of higher education in our country.

Education departments and main institutions of higher learning in our country began to employ foreign teachers in early years of the new nation. At that time, foreign teachers employed by institutions of higher learning in our country have small scale and small number and are mainly language teachers, belonging to initial stage. Since the reform and opening up, universities in our country have entered the new period of employing foreign teachers. Universities throughout the country employ foreign teachers one after another. The number of people has significant growth. With deepening of opening to the outside world, especially in recent years, the quantity and quality of foreign teachers employed by universities in our country acquire great development. It is shown in "Table I".

TABLE I. 2005-2011 NUMBER AND EDUCATION BACKGROUND OF FOREIGN TEACHERS EMPLOYED BY NATIONAL REGULAR INSTITUTIONS OF HIGHER LEARNING

\begin{tabular}{|l|l|l|l|l|l|}
\hline Year & Doctor & Master & $\begin{array}{c}\text { Bachel } \\
\text { or }\end{array}$ & $\begin{array}{c}\text { Junior college } \\
\text { and below }\end{array}$ & Total \\
\hline 2005 & 1026 & 1714 & 3162 & 83 & 5985 \\
\hline 2006 & 1653 & 2616 & 4620 & 62 & 8951 \\
\hline 2007 & 1626 & 2871 & 4886 & 50 & 9433 \\
\hline 2008 & 2503 & 2868 & 5092 & 87 & 10550 \\
\hline 2009 & 2525 & 3034 & 5001 & 88 & 10648 \\
\hline 2010 & 2849 & 3262 & 5094 & 82 & 11287 \\
\hline 2011 & 4439 & 3661 & 4784 & 181 & 13065 \\
\hline
\end{tabular}

Data source: Ministry of Education 2005-2011 education statistic data

It can be seen from the statistic data that the quantity of foreign teachers in universities of our country was 5,985 in 2005. The number is 13,065 by the end of 2011 and it is doubled. Besides, foreign teachers teaching in universities of our country have bachelor degree or above in general. Large 
quantities of foreign teachers enter universities to teach. They play a more and more important role and their status is also improved continuously. At the meantime, universities have increasingly high requirements for quantity and quality of foreign teachers. Therefore, researchers should pay attention to how to effectively promote the development of foreign teachers in universities, improve efficiency of employment and reasonably make use of the resource of foreign teachers.

\section{B. Development of Foreign Teachers in Universities}

Developed countries in Europe and America began to pay attention to the research on development of college teachers in 1950s. Our country began at the end of last century. At initial stage, they pay attention to teacher management and teaching staff construction and take teachers as object of management to research. In 1991, National Education Association (NEA) makes detailed definition of connotation of "teachers' development": Teachers' development mainly focuses on four objectives, namely personal development, professional development, teaching development and organizational development. Personal development includes improving teachers' career planning and communication ability, cultivating teachers' consciousness of self-development and giving guidance on how to effectively maintain physical fitness. Professional development refers to promote personal growth, acquire or improve knowledge, skill and consciousness related to professional work. Teaching development refers to preparations for learning materials and update of teaching model and curriculum plan. Organizational development focuses on creating effective organizational atmosphere and urging teachers to adopt new teaching practice. [2]

The author bases on scholars' research on management of foreign teachers in universities and thinks that the development of foreign teachers in universities refers to that foreign teachers teaching in universities continuously improve their professional knowledge, teaching ability and professional ethics through various theoretical learning and practice. At the meantime, related administrative departments and universities in our country shall also combine requirements of specific professional post for foreign teachers, train them, help foreign teachers faster and better to enter the post, unceasingly update knowledge hierarchy, and realize professional and teaching development, in order to adapt to teaching jobs in universities of China.

\section{Training System for Foreign Teachers in Universities}

The training system for foreign teachers in universities in this research means establishing clear training concepts for foreign teachers coming from different countries and working on teaching jobs in universities of our country, exploring reasonable pre-job training and on-the-job training for foreign teachers in universities, mobilizing and integrating enthusiasm of all aspects, comprehensively using a variety of training methods, establishing platforms for development of foreign teachers and promoting personal development, professional development and teaching development of foreign teachers in universities, and then realizing connotative development of institutions of higher learning.
Because foreign teachers in universities are from different countries and have different cultural backgrounds and values, it leads to the situation that varying degrees of differences exist in way of thinking and communication between foreign teachers and college students. It needs foreign teachers to summarize teaching experience frequently in teaching. It is more necessary for universities to strengthen training work of foreign teachers, give correct guidance and provide more development opportunity for foreign teachers. However, at present, some foreign teachers in our country lack special training from educational institution of foreign teachers and they do not participate in special vocational training on pedagogy and educational psychology for college teachers, and enter universities to teach only on the basis of their previous experience. At the same time, the training system in universities that employ foreign teachers does not perfect, which directly influence the development of foreign teachers. Therefore, it is of great significance to establish training system basing on the development of foreign teachers in universities, in order to effectively increase professional knowledge and teaching skills of foreign teachers in universities and improve human capital owned by them.

\section{BASIC CONTENTS OF DEVELOPMENT OF FOREIGN TEACHERS IN UNIVERSITIES}

The development of foreign teachers in universities is the constantly updated independent pursuit in their career. It is a continuous process that foreign teachers experience from employment to teaching adaptation and then to professional mature and develop into professional teachers. It needs external condition of training system in universities as well as personal efforts of foreign teachers. Independent development is the basic way of teaching development. The contents of development of foreign teachers in universities are specifically embodied in the following aspects:

\section{A. Shape Development Concept of Foreign Teachers in Universities}

Development concept of foreign teachers in universities pays attention to comprehensive development and lifelong development of foreign teachers and let foreign teachers have mature pursuit and yearning for their teaching ability and professional level through continuous learning and practice. Development concept is the premise for development of foreign teachers in universities. Establishing the idea of development, foreign teachers can provide powerful driving force for teaching and professional development of them in universities of China. It has important significance on the improvement of self-quality and ability of foreign teachers.

\section{B. Expand Professional Knowledge of Foreign Teachers in Universities}

As special part of teaching body in universities, compared with Chinese teachers, foreign teachers better understand custom and frontier knowledge of foreign countries and can create better atmosphere of foreign knowledge. Although most foreign teachers in universities teach language course and can be proficient in using language, it also needs them to have certain Chinese traditional cultural deposits and scientific 
literacy. Therefore, foreign teachers shall widen their scope of knowledge and ceaselessly update teaching ideas in teaching practice.

\section{Improve Teaching Skills of Foreign Teachers in Universities}

The development of teaching skills of foreign teachers in universities is the basic content of development of foreign teachers. Although foreign teachers are from different countries and have different cultural backgrounds, as teachers in universities, their basic task is teaching. They need to have knowledge on pedagogy and educational psychology and master certain teaching skills. Teaching skills are external expression of comprehensive ability of foreign teachers. Foreign teachers shall continuously develop abilities in teaching innovation, classroom management, and language expression and communicate with Chinese teachers and students in universities.

\section{Promote Professional Ethics of Foreign Teachers in Universities}

Professional ethics of college teachers refer to code of conduct followed by teachers and morality of teachers. On one hand, foreign teachers need to establish the relationship of fair cooperation and form working environment of trusting and helping each other. On the other hand, in the process of training talents, words and deeds of foreign teachers influence college students imperceptibly. Therefore, foreign teachers need to strengthen self-discipline, overcome obstructive factor, make an example and continuously improve professional ethics.

\section{Training Problems Existing In Professional DEVELOPMENT OF FOREIGN TEACHERS IN UNIVERSITIES}

The purpose of training system for foreign teachers in universities is to promote the improvement of professional skills and teaching level of foreign teachers, guarantee development of foreign teachers and then maintain the order of all universities. With increasing number of foreign teachers employed by universities, it is difficult for the existing training system in our country to meet the requirements for development of foreign teachers at the present stage. The research selects 12 universities in Liaoning province, including 120 college students and 30 foreign teachers to carry out empirical investigation of foreign teacher management in universities, and then use SPSS software to summarize the findings. This article only base on statistical results, start with the perspective of promoting training system for development of foreign teachers in universities, deeply discuss current situation of training system for foreign teachers in universities through researching different types of samples, find and analyze problems existing in it. These problems are embodied in the following aspects.

\section{A. The Understanding for Objectives and Roles of Training Is Inadequate; Neglect Comprehensive Development of Foreign Teachers in Universities}

According to statistical results, as shown in "Fig. 1", $51.7 \%$ of foreign teachers relatively agree with the opinion that "training helps to adapt to university life". There are only $6.9 \%$ of foreign teachers totally disagree with this opinion. It shows that effective training has important influence on foreign teachers in adapting to teaching and life in universities of China. However, the traditional training objectives for foreign teachers in universities of our country hold the opinion that the reason why foreign teachers need training is that foreign teachers are from different countries and have different cultural backgrounds, so certain deficiencies appear in the existing teaching methods and teaching abilities. The training objectives are limited to solving problems appearing in teaching and neglect that the training can help foreign teachers to adapt to university life and develop their education and teaching abilities. With continuous improvement of internationalization degree of higher education, the quantity of foreign teachers also presents geometric growth. It requires administrators responsible for foreign teachers to comprehensively and fully understand objectives and functions of training for foreign teachers in universities and establish specific training system for foreign teachers.

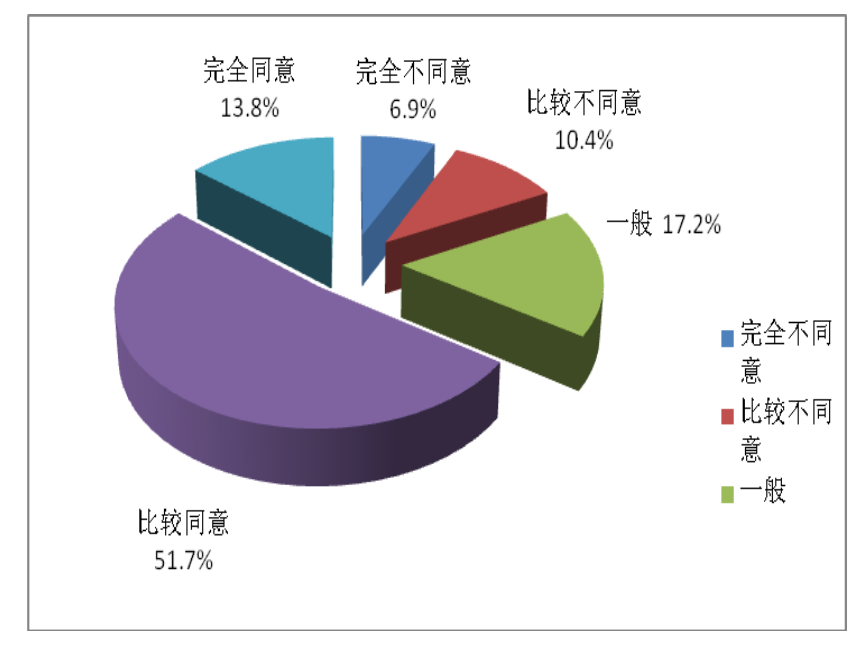

Fig. 1. Level of agreement of foreign teachers in universities on the opinion that "training helps to adapt to college life"

\section{B. The Training Content Is Too Single, Difficult to Meet the Requirements of Foreign Teachers Development in Universities}

According to the investigation, the current training contents of foreign teachers are too single. Most of them are limited to theoretical training and uniform. It can be seen from figure 2 that there are only three foreign teachers who totally agree the opinion that "the pre-job training is very comprehensive", accounting for $10.3 \%$ of the overall number of people. The training for professional ethics is more inadequate, which lead to the situation that some foreign teachers don't have enough professional dedication. Previous training system doesn't have requirements for development of foreign teachers and put forward corresponding requirements for training contents of 
foreign teachers by stages, so it is difficult to stimulate interest of foreign teachers in training and the training effects are not prominent. Therefore, it is necessary to continuously enrich training contents of foreign teachers in universities and adopt different training contents for foreign teachers in different universities from different countries.

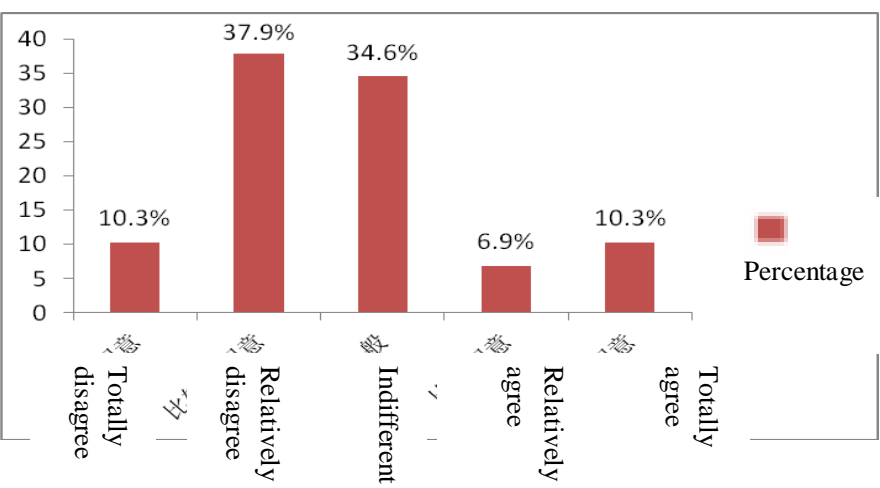

Fig. 2. Level of agreement of foreign teachers in universities on the opinion that "pre-job training is very comprehensive"

\section{The Training Course Becomes Formalistic, Which Is Difficult to Improve Ability of Development of Foreign Teachers in Universities}

The existing training course of foreign teachers in universities becomes formalistic. It mainly shows that the thinking of administrators responsible for training of foreign teachers is backward. They do not start with long-term development of universities as well as realize the maximum benefit in employing foreign teachers. Besides, they only pay attention to cultural background and education background of foreign teachers and think little of development training and degree of training for foreign teachers after the employment. The training also becomes formalistic. The survey results indicate: The proportion of foreign teachers with one to three months of pre-job training is maximum, accounting for $62 \%$ of the total number; there is only one foreign teacher with three to six months of pre-job training; the number of foreign teachers with more than twelve months of pre-job training accounts for $35 \%$. Some foreign teachers have not participated in pre-job training, which influences the development of foreign teachers to a certain degree. Therefore, it is necessary to strengthen comprehensive feedback of training for foreign teachers and make the training obtain sustainable impetus.

\section{Measures to Construct Training System to PROMOTE DEVELOPMENT OF FOREIGN TEACHERS IN UNIVERSITIES}

The rapid growth of number of foreign teachers has close relationship with historical background of higher education internationalization. It is an important measure for internationalization of higher education to employ foreign teachers to work on teaching jobs in universities of our country. Although the number of foreign teachers employed by universities unceasingly grows, it is difficult to ensure teaching quality of foreign teachers. A series of problems also appear in the existing training system for foreign teachers in universities. Therefore, we should actively take effective measures and provide constructive suggestions to build training system to promote comprehensive development of foreign teachers in universities.

\section{A. Scientific Pre-job Training Is the Key to Strengthen Development Ability of Foreign Teachers in Universities}

Pre-job training is the professional training before newlyappointed foreign teachers begin to work, and the essential condition of confirmation of foreign teacher qualification in universities. Newly-appointed foreign teachers in universities must participate in pre-job training organized by national and regional administrative departments for education or related administrative departments in universities. They can teach after getting certificate of approval, and then participate in other related training after being employed. Pre-job training can help foreign teachers to understand related contract terms of universities and their rights and obligations. [3] In order to improve overall quality of foreign teachers, scientific pre-job training needs to:

First, establish advanced idea of pre-job training. Concrete measures include: At the beginning of pre-job training, pay attention to training the concept of foreign teachers in universities to have independent development and gradually help foreign teachers to change the traditional idea that they are only responsible for teaching in universities. They shall also attach importance to teaching reflection, carry out afterclass summary and improve overall quality step by step through learning and communicating with other teachers; organize foreign teachers to enrich forms of self-development. In pre-job training, let foreign teachers learn to write teaching diary [4], often record changes of their thoughts and behaviors. Through teaching reflection, foreign teachers can promote the development of teaching awareness and ability.

Second, set clear objectives of pre-job training. Pre-job training departments for foreign teachers in universities of our country need to base on requirements put forward by higher education development for foreign teachers, combine with types of foreign teachers needed by universities, take life-long education concept as guidance and design pre-job training programs that have innovation thinking and conform to requirements of professional development of foreign teachers according to characteristics of professional development of foreign teachers.

Third, enrich contents of pre-job training. The pre-job training for foreign teachers should be comprehensive and rich to improve professional ability of foreign teachers. The contents of pre-job training not only include Language of China, cultural background, basic teaching skills, business level and ideology and politics, but also cover trainings such as computer knowledge, classroom teaching methods, curriculum theory and professional ethics of college teachers, to make training contents more complete and systematic and promote comprehensive development of foreign teachers. 


\section{B. Effective On-the-job Training Is the Guarantee to Improve Development Quality of Foreign Teachers in Universities}

On-the-job training for foreign teachers in universities is essential. Because the time of pre-job training for most foreign teachers is relatively short, the training contents are not comprehensive, even some foreign teachers do not participate in any pre-job training, it leads to the situation that they lack understanding for teaching system in universities. On-the-job training can help foreign teachers to better adapt to teaching management situation of universities in China and let foreign teachers get continuous and effective development on occupation. On-the-job training is mainly embodied in the following aspects:

The first is coordinated organization of on-the-job training. Administrative organs of on-the-job training should cooperate and coordinate with organizations of pre-job training, exert advantages of each other and avoid repeated training. Departments for training foreign teachers should be independent as well as correlate to jointly provide high quality service for development of foreign teachers.

The second is cohesive contents of on-the-job training. The on-the-job training contents for foreign teachers shall not repeat or simply supplement the contents of pre-job training but base on contents of pre-job training, aim at the development of foreign teachers, base on characteristics of foreign teachers at each development stage to design training objectives and contents, let pre-job training and on-the-job training realize cohesive development to jointly promote the development of foreign teachers in universities. It is necessary to train foreign teachers about education policies and regulations to make them understand related policies and management system of the school.

The third is comprehensive supervision and feedback of on-the-job training. Universities shall arrange supervisor for foreign teachers and establish foreign teacher development committee, regularly supervise teaching of foreign teachers to let foreign teachers at different career stage get professional development. [5] Meanwhile, universities shall let college students participate in teaching evaluation for foreign teachers at fixed period through forms such as questionnaire and interview and carry out on-the-job training for foreign teachers.

To sum up, when universities of our country intensify the introduction of foreign teachers, they should also pay attention to connotative development of foreign teachers, use scientific development idea to guide training for foreign teachers, set clear training objectives, arrange rich training contents, apply modern training means, and adopt diversified training methods to form scientific and sound training system for foreign teachers, in order to meet the requirements of development of foreign teachers in universities and improve the quality of talent training of higher education.

\section{REFERENCES}

[1] Shi Wanbing, Yan Dan, Zhang Yuxin. Discussion on Education Administration Measures to Boost Internationalization Process of Higher Education in Our Country $[\mathrm{J}]$, Journal of Liaoning Administration College, 2004, (1): 100-101
[2] National Education Association .Faculty Development in Higher Education :Enhancing a National Resource[M].A Booklet in the Series to Promote Academic Justice and Excellence .Washintion, DC, 1992: 11-12.

[3] Zhang Xiaoyan, Guo Feng. Reasons for Difficulties in Employing Foreign English Teachers in Universities and Countermeasures [J], China Higher Education, 2011, (8): 56-57

[4] Wang Hui, Yuan Xiaolu. Research on Education Action and Analysis on Professional Development of Foreign Teachers [J], Journal of Ningxia Teachers College, 2012, (5):105-106

[5] Gaff , J.C. Toward Faculty Renewal: Advances in Faculty , Institutional, and Organizational Development [M].San Francisco: Josses-Bass， 1975:14. 